\title{
Kist hidatik cerrahisinde anestezi yönetimi; 321 hastanın retrospektif analizi
}

\section{Anesthesia management in hydatid cyst surgery; a retrospective analysis of 321 patients}

\author{
Erdoğan Duran ${ }^{1}$, Nuray Altay1 ${ }^{1}$ \\ 1 Harran Üniversitesi, Tıp Fakültesi Araştırma ve Uygulama Hastanesi. Anesteziyoloji ve Reanimasyon A.D.
}

Öz.

Amaç: Kist hidatik hastalığı, ülkemizde, özellikle Doğu ve Güneydoğu Anadolu Bölgesi'nde ve ilimizde ciddi bir sağlık problemidir. Hidatik hastalık, Echinococcus granulosus ve Echinococcus multilocularis tarafından oluşturulan bir protozoal hastalıktır. İnsanların karaciğer, akciğer, dalak ve beyin gibi iç organlarında kistler oluşturarak ölüme kadar giden istenmeyen sonuçlara yol açabilmektedir. Bu çalışmada kist hidatik hastalığı nedeniyle ameliyat yapılan hastalarda anestezi deneyimlerimizi değerlendirmeyi amaçladık.

Materyal ve Metot: Bu çalışmada; Ağustos 2015- Ağustos 2018 tarihleri arasında, Harran Üniversitesi Araștırma ve Uygulama Hastanesi ameliyathanesinde kist hidatik ön tanısıyla ameliyat olan hastaların demografik verileri, uygulanılan anestezi yöntemi, anaflaksi oluşup oluşmadığı, hangi organ tutulumu olduğu retrospektif olarak incelendi.

Bulgular: Çalışmamıza, kist hidatik tanısıyla hastanemizde cerrahi tedavisi yapılan 321 hasta dahil edildi. Hastaların \% 33,33'ü $(n=107)$ erkek, \% 66,66'sı $(n=214)$ kadındı. Bu hastaların \%25,85'i $(n=83) 18$ yaş altı pediatrik hasta, \%74,17'ü $(n=238)$ yetişkin hasta idi. Hastaların \%55,76'sında $(n=179)$ karaciğer, \%36,44'ünde $(n=117)$ akciğer, \% 3,11'inde $(n=10)$ akciğer ve karaciğer, \% 2,18'inde $(n=7)$ böbrek, \% 1,24'ünde $(n=4)$ kalp, \% 0,93'ünde $(n=3)$ beyin, \% 0,31'inde $(n=1)$ pelvik tutulum vardı. Hastalarda intraoperatif alerji ve anaflaktik reaksiyon bulgusu not edilmemiştir.

Sonuç: Kist hidatik hastalığında operasyon sırasında anaflaktik reaksiyon ciddi bir komplikasyon olup nadiren görülmektedir. Kist hidatik ameliyatlarında intraoperatif antihistaminik ve steroidin rutin kullanımının alerji ve anaflaksiyi azalttığını düşünmekteyiz.

Anahtar kelimeler: Anaflaksi, Anestezi, Kist Hidatik

\section{Abstract}

Background: Hydatid cyst disease is a serious health problem in our country, especially in Eastern and Southeastern Anatolia Region and in our province. Hydatid disease is a protozoal disease caused by Echinococcus granulosus and Echinococcus multilocularis. It can produce cysts in the internal organs of humans such as liver, lungs, spleen and brain, leading to undesirable consequences. In this study, we aimed to evaluate our anesthesia experience in patients who underwent surgery for hydatid cyst disease.

Methods: In this study; Between August 2015 and August 2018, demographic data, anesthesia method, anaphylaxis and organ involvement were investigated retrospectively in patients operated with pre-diagnosis of hydatid cyst in Harran University Research and Application Hospital operating room.

Results: 321 patients who underwent surgical treatment in our hospital with the diagnosis of hydatid cyst were included in the study. 33.33\% $(n=107)$ of the patients were male and $66.66 \%(n=214)$ were female. Of these patients, 25.85\% ( $n=83$ ) were pediatric patients under the age of 18 and $74.17 \%(n=238)$ were adult patients. Patient's had hydatid cyst organ involvement in liver $55.76 \%(n=179)$, in lungs $36.44 \%(n=117)$, in both lungs and liver 3.11\% ( $n=10)$, in kidney 2.18\% ( $n=7)$, in heart 1.24\% ( $n=4)$, in brain $0.93 \%(n=3)$, and $0.31 \%(n=$ 1) of patients had pelvic involvement. Intraoperative allergy and anaphylactic reaction findings were not noted. Conclusion: Anaphylactic reaction is a serious complication in hydatid cyst disease and rarely seen. We think that intraoperative antihistaminic and steroid use in cyst hydatid surgery decreases allergy and anaphylaxis.

Key words: Anaphylaxis, Anesthesia, Hydatid Cyst

\section{Sorumlu Yazar I Corresponding Author}

Dr. Erdoğan Duran

Harran Üniversitesi, Tıp Fakültesi Araştırma ve Uygulama Hastanesi. Anesteziyoloji ve Reanimasyon A.D.

Tel: +904143444444

E-mail: drerdoganduran6331@gmail.com

Geliş tarihi / Received: 11/07/2019

Kabul tarihi / Accepted: 02/08/2019

DOI: $10.35440 /$ hutfd. 590805 


\section{Giriş}

Kist Hidatik (KH), Echinococcus granulosus ve Echinococcus multilocularis tarafindan oluşturulan bir protozoal hastalıktır. Hastalığın bulaşmasında etken olan parazitler başta karaciğer ve akciğer olmak üzere birçok organ ve doku tutulumu yaparak ölüme kadar gidebilen klinik tablolara yol açabilmektedir. KH için farklı tedavi yöntemleri olmakla birlikte, genel anestezi altında cerrahi olarak çıkarıması en yaygın tedavi yöntemi olarak güncelliğini korumaktadır. Hastalık ülkemizde Güneydoğu ve Doğu Anadolu bölgelerinde sık görülmekte, ekonomik ve sosyal boyutuyla da hala ciddi bir sağlık problemi olmaya devam etmektedir. Hastalığın özellikleri ve kullanılan tedavi yönteminin sıklığı dikkate alındığında anaflaksi riski açısından da kullanılan anestezi yöntemleri ve yaklaşımları önem arz etmektedir $(1,2)$. Bu çalışmada $\mathrm{KH}$ nedeniyle opere olan 321 hastanın preoperatif ve intraoperatif verileri incelendi.

\section{Materyal ve Metot}

Etik kurul onayı (Harran Üniversitesi Etik Kurulunun 06.09.2018 tarih, 09 nolu oturum ve 01-02-03 nolu kararları) alındıktan sonra, Ağustos 2015- Ağustos 2018 tarihleri arasında, Harran Üniversitesi Araştırma ve Uygulama Hastanesi ameliyathanesinde $\mathrm{KH}$ ön tanısıyla ameliyat olan hastaların verileri değerlendirildi. Hastaların demografik özellikleri (yaş, cinsiyet), organ tutulumu, uygulanan anestezi yöntemleri, premedikasyon için uygulanan ilaçlar, indüksiyon ve anestezi idamesi sırasında kullanılan anestezik ilaçlar, intraoperatif ve postoperatif komplikasyonlar, hasta dosyaları ve anestezi kayıtları incelenerek not edildi. Elde edilen verilerde istatistiksel yöntem olarak yüzdelik değerlendirme kullanıldı.

\section{Bulgular}

Çalışmamıza, KH tanısıyla hastanemizde genel anestezi altında açık cerrahi yöntemle tedavisi yapılan 321 hasta dahil edildi. Hastaların \% 33,33'ü $(n=107)$ erkek, \% 66,66 'sı $(n=214)$ kadındı. Bu hastaların \% 25,85'i $(n=83)$ 18 yaş altı pediatrik hasta, $\% 74,17$ 'ü $(n=238)$ yetişkin hasta idi. En genç hasta 1 yaşında, en yaşlı hasta 80 yaşında idi. 321 hastanın \% 55,76'sında $(n=179)$ karaciğer, $\% 36,44$ 'ünde $(n=117)$ akciğer, $\% 3,11$ 'inde $(n=10)$ akciğer ve karaciğer, \% 2,18'inde $(n=7)$ böbrek, $\% 1,24$ 'ünde $(n=4)$ kalp, \% 0,93'ünde $(n=3)$ beyin, \% 0,31'inde $(n=1)$ pelvik tutulum vardı (Tablo 1, 2).

Çalışmamıza dahil edilen hastalarda intraoperatif alerji ve anaflaktik reaksiyon bulgusuna rastlanmadı. Beyin tutulumu olan $3(\%, 0,934)$ hastada indüksiyonda hipnotik ajan olarak tiyopental, geri kalan $318(\% 99,065)$ hastada ise propofol kullanıldığı görülmüştür. Yine indüksiyonda opioid ajan olarak fentanil ve kas gevşetici olarak roküronyumun uygulandığı tespit edildi. Anestezinin idamesinde fentanil, roküronyum ve inhaler anestezik ajan olarak sevofluran ve desfluran kullanıldığı kaydedildi.
Tablo 1. Hastaların demografik özellikleri

\begin{tabular}{ll}
\hline Cinsiyet & \\
\hline Kadın & $214(\% 66,66)$ \\
Erkek & $107(\% 33,33)$ \\
\hline Yaş (1-80) & \\
\hline$>18$ & $238(\% 74,17)$ \\
$<18$ & $83(\% 25,85)$ \\
Toplam hasta & 321 \\
\hline
\end{tabular}

Tablo 2. Kist hidatik lokalizasyonu

\begin{tabular}{ll}
\hline Lokalizasyon & \\
\hline Karaciğer & $179(\% 55,76)$ \\
Akciğer & $117(\% 36,44)$ \\
Akciğer + Karaciğer & $10(\% 3,11)$ \\
Böbrek & $7(\% 2,189)$ \\
Kalp & $4(\% 1,24)$ \\
Beyin & $3(\% 0,939)$ \\
Pelvik tutulum & $1(\% 0,31)$ \\
\hline
\end{tabular}

\section{Tartışma}

$\mathrm{KH}, 17$. yüzyıldan beri bilinen bir hastalıktır. Türkiye, Orta Doğu, Avustralya, Güney Amerika, Hindistan'ın bazı bölgelerinde hala önemli bir sağlık problemidir (3). Parazit taşıyan taşıyıcılar ile sürekli temasta bulunan insanlarda ve bazı coğrafi bölgelerde daha sık görülmektedir. Hastalık, ülkemizde Avrupa ve diğer gelişmiş ülkelere göre on kat daha fazla görülmektedir. Hastalığın prevalansı 100 binde 50 , insidansı ise 100 binde 2 - 12 arası oranlarda bildirilmektedir. Türkiye'de insidansı \% 14 olarak bildirilmektedir. Ancak bölgesel farklılıklar ve görülme insidansında ciddi oranlarda farklılklar mevcuttur. Özellikle Doğu- Güneydoğu Anadolu bölgeleri hastalığın endemik olarak bulunduğu yörelerdir. Bu bölgelerde prevalans değerlerinin 100 binde 300 - 400'lere kadar çıktığını belirten kaynaklar bulunmaktadır. Gelişmiş tanı ve tedavi yöntemlerine rağmen \% 3,5 - 18 arasında morbidite, \% 0 - 2 arasında mortalite söz konusudur (3-5).

Erişkin ekinokok türleri son konak olan köpek, kedi gibi etobur hayvanların ince bağırsak mukozasına bağlanır. Parazit yumurtaları hayvanların dışkıları ile ortama yayılır. Ara konak olarak insanlara, kontamine olmuş yiyeceklerle sindirim yolu ile bulaşır. Yumurtadan çıkan embriyolar intestinal mukozadan kana geçer, portal ven ve lenfatikler yoluyla tüm dokulara yayllabilir $(2,6)$.

Literatürde yerleşim yerleri olarak karaciğere $\% 50-70$, akciğere $\% 11-17$, yumuşak dokulara $\% 2,4-5,3$, kalbe $\%$ 0,5 - 3, perikarda $\% 5$, kas ve subkutan dokulara $\% 0,5$ 4,7 olduğu bildirilmiştir. Bizim çalışmamızda da literatür ile uyumlu olarak olguların $\% 55,76$ 'sında karaciğer tutulumu, ikinci sıklıkta da olguların \% 36,44'sında akciğer tutulumu olduğu görülmüştür. Hastalarımızın \% 3,11'inde $(n=10)$ akciğer ve karaciğer, \% 2,18'inde $(n=7)$ böbrek, $\%$ 1,24'ünde $(n=4)$ kalp, \% 0,93'ünde $(n=3)$ beyin, $\%$ 
0,31 'inde $(n=1)$ pelvik tutulum vardı. Daha önce kliniğimizde yapılmış olan çalışmada kalp tutulumuna rastlanmamışıı (2). Farklı zaman aralıklarını kapsayan bizim çalışmamızda toplam 4 adet kalp tutulumu olgusu mevcuttu. Yine aynı çalışmada dalak tutulumu olguları bildirilmiş olup bizim çalışmamızda ise dalak tutulumu olgusuna rastlanmamıştır. Bu sonuçlarla literatürde nadir görülen organ tutulum oranları ile bizim çalışmamız uyum göstermektedir. Hastalık her yaşta görülebilmekle beraber, daha sık erişkinlerde ve kadınlarda görülmektedir. Geniş vaka çalışmaları incelendiğinde kadınlarda görülme oranını \% 51,2 ile $\% 77$ arasında bildiren yayınlar vardır (7-10). Bizim çaış̧mamızda da kadınların oranı \% 66,66 ile literatürle uyumlu olarak tespit edildi. Hastalarımızın \% 74,17'ü ( $n=$ 238) yetişkin hasta, $\% 25,85^{\prime} i(n=83) 18$ yaş altı pediatrik yaş grubu idi. Ülkemiz ve bölgemiz için hala yaygın bir sağlık sorunu olarak önemini koruyan KH ile ilgili yapılan çalışmalarda, çocuk yaş grubunda görülme sıklğıyla ilgili farklı veriler bulunmakta olup, yaptığımız literatür taramasında ülkemizde hastalığın çocuklarda görülme sıklğına ait bir veriye rastlayamadık. Çalışmamızda 18 yaş altı $\mathrm{KH}$ tanıı çocukların oranı $\% 25,85$ olarak bulunmuş olup, yaklaşık olarak her dört hastadan birinin çocuk yaş grubunda olması, hastalığın genelde belirti vermemesi de göz önünde bulundurulduğunda, hastalığın çocuklarda görülme sıklığının daha yüksek bir oranda olduğunu düşündürmektedir. Medikal tedavisi mümkün olan bu hastalığın çocuklarda cerrahi tedavi intiyacı doğurması, bu hasta grubundaki anestezi ve cerrahiye bağlı tedavi maliyeti ile bunlara bağlı komplikasyonları da beraberinde getirmesi açısından önem arz etmektedir.

Genellikle belirti vermeyen $\mathrm{KH}$ çoğunlukla tesadüfen teşhis edilmektedir. Klinik belirtileri yerleştiği bölgeye ve kist boyutuna göre değişiklik gösterebilir. En sık görülen karaciğer tutulumunda genellikle sağ batın üst bölgede künt ağrı, bulantı, halsizlik, ateş gibi non spesifik belirtiler görülebilir. Akciğer tutulumunda basıya bağlı yan ağrısı, öksürük ve hemoptizi görülebilir (2). Bizim çalışmamızda da hastaların hastaneye başvuru şikayetleri hastalığın yerleştiği organa göre idi.

KH' de tedavinin amacı, paraziti vücuttan uzaklaştırmak, komplikasyonlara engel olmak ve nüksü önlemektir. Uygun vakalarda perkutan tedavi yöntemleri de uygulanmakta olup, cerrahi tedavi hala en önemli tedavi seçeneği olarak güncelliğini korumaktadır. Kist rüptürü travmaya bağlı ya da spontan olabilmektedir. Bu olgularda anafilaksi ve ani ölüm oranı $\% 25$ olarak bildirilmiştir (11). Bazı kaynaklarda perioperatif dönemde anafilaksi insidansının nadir olduğu ve 1/6.000-1/20.000 arasında olduğu, tahmini ölüm oranının da \% 3 - 6 arasında olduğu ifade edilmektedir (12, 13). Anafilaktik reaksiyon çeşitli organ sistemlerini etkileyebilir. Respiratuar (bronkospazm ve üst solunum yolu tikanması), kardiyovasküler (hipotansiyon ve aritmi), dermatolojik (ürtiker ve anjiyoödem) ve gastrointestinal (bulantı ve kusma) bulgular gözlemlenebilir. Bulguların büyük bir kısmı genel anestezi altında görülmeyebilir. Genel anestezi sırasında hipotansiyon, bronkospazm ve ürtiker ana semptomlardır $(14,15)$. Yapılan bazı çalışmalarda anaflaktik reaksiyonlardan kaçınabilmek için proflaktik kortikosteroid ve antihistaminiklerin kullanımı önerilmektedir. Yaptığımız bu çalışmada hastalarda intraoperatif alerji ve anaflaktik reaksiyon bulgusu not edilmemiştir. Biz de bunu operasyonun başında yapılan antihistaminiklere ve kortikosteroidlere $(0,1 \mathrm{mg} / \mathrm{kg}$ deksametazon, $1 \mathrm{mg} / \mathrm{kg}$ feniramin) bağlamaktayız. Bu yüzden biz de operasyonun başında proflaktik olarak kortikosteroid ve antihistaminiklerin kullanımını önermekteyiz. Bununla birlikte, hastanın yakın takibi yapılmalı, kist eksizyonu sırasında periferik oksijen satürasyonunda ani ve kalıcı düşme, şiddetli hipotansiyon ve yaygın eritem gibi semptomların görülmesi durumunda öncelikle, kist rüptürüne bağlı, yüksek oranda antijenik madde içeren kist sıvısının, kan dolaşımına karıştığı düşünülerek anafilaksi prosedürü uygulanmalıdır $(12,16)$.

Sonuç olarak, kırsal bölgelerdeki çocuk nüfusta yüksek oranda görülmeye devam eden $\mathrm{KH}$ hastalığının gelecekte ciddi sağlık sorunlarına neden olabileceği düşünüldüğünde, hastalı̆ı̆ın endemik olarak görüldüğü ülkelerde öncelikli hedef hastalı̆ı önlemek olmalı, rezervuarın azaltımasıyla ilgili çalışmalara öncelik verilerek hastalığın bulaşmasının önüne geçilmelidir. Ayrıca, $\mathrm{KH}$ ' li vakalarda cerrahi tedavi hala ilk tercih olmaya devam etmektedir. KH hastalığında operasyon sırasında anaflaktik reaksiyon ciddi bir komplikasyon olup nadiren görülmektedir. Bu vakalarda intraoperatif olarak alerji ve anaflaktik reaksiyon proflaksisi için ameliyatın başlangıcında alınan cerrahi tedbirlerin, antihistaminiklerin ve steroidlerin proflaktik kullanımının, alerji ve anafilaksi komplikasyonunu azalttığını düşünmekteyiz. Çalışmamızdaki limitasyon, hastanemizde sadece açık cerrahi tedavi yöntem uygulanan hasta verilerinin olması, diğer cerrahi yöntemler ve perkütan yöntemle $\mathrm{KH}$ tedavisi yapılan hasta grubunun olmaması, bu tedavi yöntemlerine bağlı komplikasyonların bilinmesine engel olmuştur. Bu nedenle yaş gruplarına göre daha geniş çaplı, farklı cerrahi tedavi yöntemleri ve peruktan yöntemle KH tedavisi sırasında oluşabilecek komplikasyon verilerine ulaşılabilecek araştırmalara intiyaç bulunmaktadır.

\section{Kaynaklar}

1. Khanfar N. Hydatid disease: a review and update. Current Anaesthesia \& Critical Care 2004, 15: 173-83

2. Altay $N$, Yüce $H H$, Küçük $A$, Aydoğan $H$, Yalçın Ş, Yıldırım ZB. Anesthetic management in hydatid disease: a review of 435 cases. Clin Ter 2014; 165 (2):e90-93

3. Burgos R, Varela A, Castedo E, et al. Pulmonary hydatidosis: surgical treatment and followup of 240 cases. Eur J Cardiothorac Surg 1999; 16: 628-35

4. Yüksel M, Kalaycı G. Akciğer kist hidatiğinin cerrahi tedavisi. In: Yüksel M, Kalaycı G eds. Göğüs Cerrahisi. İstanbul, Özlem Grafik Matbaacılık, 2001:647-658.

5. Şahin E, Kaptanoğlu M, Nadir A, Ceran C. Travmaya bağlı bir akciğer kist hidatiği rüptürü: Olgu sunumu. Ulus Travma Derg 2006; 
12:71- 75

6. Bulbuller N, Ilhan YS, Kırkıl C, et al. The results of surgical treatment for hepatic hydatid cysts in an endemic area. Turk J Gastroenterol 2006; 17(4):273-8

7. Milicevic M, Saidi F, Sayek İ. Karaciğer kist hidatiği. In: Sayek I, editor. Temel cerrahi. 3rd ed. Ankara: Güneş Tıp Kitapevi; 2004. s. 1317-24.

8. Çörtelekoğlu AT, Beşirli K, Yüceyar L, Bozkurt K, Kaynak K, Tüzün $\mathrm{H}$, ve ark. Atipik yerleşimli kist hidatik. Türk Göğüs Kalp Damar Cer Derg 2003; 11:195-7.

9. Köksal AŞ, Arhan M, Oğuz D. Kist hidatik. Güncel Gastroenteroloji 2004;8:61-7.

10. Doğan Albayrak, Yavuz Atakan Sezer, Abdil Cem İbiş, Mehmet Ali Yağcl, Ahmet Rahmi Hatipoğlu, İrfan Coşkun. Karaciğer Kist Hidatik Olgularımız. Trakya Univ Tip Fak Derg 2008;25(2):95-99

11. Ozturk G, Aydinli B, Yildirgan MI, Basoglu M, Atamanalp SS, Polat $\mathrm{KY}$, et al. Posttraumatic freeintraperitoneal rupture of liver cystic echinococcosis: a case series and review of literature. Am J Surg 2007; 194:313-6.

12. Khanna P, Garg R, Pawar D. Intraoperative anaphylaxis caused by a hepatic hydatid cyst. Singapore Med J. 2011;52:E18-E19.

13. Nel L, Eren E. Peri-operative anaphylaxis. Br J Clin Pharmacol. 2011;71:647-658.

14. Hepner DL, Castells MC. Anaphylaxis during the perioperative period. Anesth Analg. 2003;97:1381-1395.

15. Laxenaire MC, Mertes PM. Anaphylaxis during anaesthesia. Results of a two-year survey in France. Br J Anaesth. 2001;87:549558.

16. Kambam JR, Dymond R, Krestow M, Handte RE. Efficacy of histamine $\mathrm{H} 1$ and $\mathrm{H} 2$ receptor blockers in the anesthetic management during operation for hydatid cysts of liver and lungs. South Med J. 1988;81:1013-1015. 